\title{
Spatial Analysis of Factors Influencing Birth Patterns in the States of India: 1985-2011
}

\author{
R. Pandey ${ }^{*}$, C. Kaur \\ Department of Statistics, University of Delhi, Delhi, India \\ Received 4 August 2016, accepted in final revised form 24 November 2016
}

\begin{abstract}
Over the past six decades, numerous demographers have studied fertility patterns of the states of India. These analyses portray a fertility decline - rapid in some states and low or moderate in others. The present paper seeks to examine the potential factors responsible for regional demographic heterogeneity in the states of India based on empirical analysis of the birth counts for the period 1985-2011.This article establishes the interactive linkages between observed fertility and the changes in four principal potential causal forces such as literacy of parents and welfare initiatives by the government in the form of public expenditure and urbanisation drive. Among the individual effects female literacy is found to promote births significantly while higher male literacy is accompanied by lower occurrences of births. Government interventions and controls such as high infrastructure spending and urbanization process result in significantly reduced births. We utilize various spatial models to determine the diffusion effect of these factors on the fertility outcomes in the neighbouring interconnected regions and interpret them.
\end{abstract}

Keywords: Fertility; Concentration Ratio; D-statistic; t-statistic; Panel Data Models; Spatial Models.

(C) 2017 JSR Publications. ISSN: 2070-0237 (Print); 2070-0245 (Online). All rights reserved. doi: http://dx.doi.org/10.3329/jsr.v9i1.29134 J. Sci. Res. 9 (1), 43-56 (2017)

\section{Introduction}

Fertility is a vital component of population growth as it provides information on the women's reproductive behavior. Literature suggests that fertility outcomes are linked indigenously to the social, economic and cultural transformations, in direct or indirect ways, which accordingly impacts the demographic structure of the countries [1]. Direct linkage among economic variables and fertility rates with the underlying assumption that impact social change will be nested in the economic

${ }^{*}$ Corresponding author: ranjitapandey111@gmail.com 
structure, subsequently influences the fertility [2,3]. Influence of economic condition on fertility outcome has also been studied [4]. Regional dissimilarity in the total fertility rate over the past years has attracted many researchers to understand and articulate the variations in fertility along with reasonable explanations. North-South differences in parity-specific fertility intentions exist in India. Prior analyses have focused on north-south dichotomy which is evident in the divergent fertility patterns across the broad physical contours of India [5]. Hence, changes in fertility desires and their actualization may be better understood within the broader socio-politico-economic context. Socio-economic factors and those related to women's status are not adequate to capture the variations in fertility decline since the nature of relationship found between female employment and fertility in developed countries is either absent or weak in the developing countries. More than employment by itself, employment type determines reproductive intentions and behavior [6,7]. Such studies point out that economic factors contribute to the fertility reduction. However, in India, non-economic forces such as cultural and religious norms explain greater proportion of fertility variations [8].

The gendered nature of Indian society favor sons more than daughters and regards them as future investment. The prevalent fertility pattern among neighbouring households extensively influences the fertility intention of households. Technological interventions (access to technologies that help to eliminate gender selective births as well as birth control means) are crucial in determining the actual size of household which is directly linked to the infrastructure availability such as health centres. Factors such as delayed age of marriage, increase in woman's individuality and aspirations for the quality of children, opportunities for personal advancement, awareness of social mobility, desire for lesser number of children and exposure to means of family planning, collectively regulate fertility $[9,10]$.

In northern parts of India (Bihar, Uttar Pradesh, Madhya Pradesh, Rajasthan, Punjab and Haryana) disenchantment with son preference, over the time, resulted in restricted and smaller family size [11]. Studies assert that direct and indirect influence of education, urbanization and exposure to mass media have supported lowering of fertility levels. Studies suggest that fertility decline in India is primarily shaped by increased contraceptive prevalence rates among the educated women [12,13]. In contrast, using the decomposition method, contraceptive prevalence among uneducated has been shown to contribute more than two-fifths of reduction in total fertility rate (TFR), between 1992-93 and 2005-06, and the remaining proportion is attributed to literate women [14].

Composite Indian fertility count behavior based on socio-economic exogenous variables has recently been studied [15]. Present study empirically investigates individual states within India motivated by the results of another empirical study focussed on Indian fertility convergence which asserts that 
'change point of fertility' theory implies that 'subset of states' of a particular region are more homogeneous with respect to fertility outcomes [16]. Assuming fertility decline to be self sustained, another recent work confirms the presence of geographic heterogeneity of the contours of fertility decline in India over the past four decades [17]. Changes in Total Fertility Rate over time (1992-2006) and space (states) in India have been empirically analysed for extent of influence exercised by the conceptual factors such as the desired family size, unwanted births, son preferences and postponement of fertility [18].

The present article is a comprehensive empirical assessment of trends and four selected determinants of fertility among the states of India, for the period 1985-2011 with the primary objective of capturing pattern shift in fertility over time. Methodological tools such as Concentration ratio (CR), D-statistic and tstatistic are used to investigate non-uniformity, spatial dependence and temporal changes in the number of births. Spatial and non-spatial models examine fertility and their potential determinants over timeline of three decades. The present paper acknowledges the role and interconnection of governance measure such as social infrastructure expenditure, individuality effects such as literacy rate and role of society in the form of urbanization rate, on fertility, through assessment of fertility concentration and transition.

The paper is organized as follows. Section 2 describes data and its sources, variables and methodology used. Section 3 is devoted to the empirical analysis and summarizes the role of causal forces linked with the emergent transformations in the births which are interpreted from policy perspectives. Section 4 concludes findings of the study with some policy suggestions.

\section{Data Source, Variables and Methodology}

To empirically evaluate the growth, decline or stability in births across Indian states literacy rate (male and female), urbanization and social infrastructure expenditure are selected as control variables. Social infrastructure expenditure comprises government expenditure on education, sports, art and culture, family welfare, medical and public health [19]. Urbanisation data is sourced from the literature [20]. Data for number of births and literacy rate is collected from the office of Registrar General of India and Census Commissioner. Births per represented in million population(s) are considered instead of fertility rate for ease of methodological requirement and consistency in the accessibility.

The study is based on balanced panel data with time period 1985 to 2011 divided in two time spans: pre 2000 and post 2000, as new states were formed through division of existing states in the year 2000. Formation of Jharkhand from Bihar, Chhattisgarh from Madhya Pradesh and Uttaranchal from Uttar Pradesh increased the total number of states (and union territories) from 32 to 35 . Therefore, the present spatio-temporal analysis is carried out separately for the 
non-overlapping and mutually exclusive time frames spanning 1985-2000 and 2001-2011, respectively. The details (definition and source) of the variables used for the analysis are reported in Appendix (see Table A.1).

\subsection{Concentration ratio (CR) of birth}

So far, economists, regional planners and geographers have used location quotient (LQ) to quantify the degree of relative concentration of an activity in the analysis of area localization. We define concentration ratio (CR) to represent birth concentration in a geographic area as

$C R_{t}^{i}=\frac{X}{Y}$ where $X=\left(\frac{B_{t}^{i}}{\sum_{t=1}^{n} B_{t}^{i}}\right)$ and $Y=\left(\frac{T B_{t}}{\sum_{t=1}^{n} T B_{t}}\right), B_{t}^{i}$ represents the level of activity (number of births) at time $t$ in state $i, T B_{t}$ represents the level of activity at time $t$ in the base state and $n$ denotes the number of time points. The value of $C R_{t}^{i}$ $>1 /<1 /=1$ indicates relative birth concentration at timet is more/less/equal compared to the overall India (see Table 1).

\subsection{D-statistic}

D-statistic, a non-parametric rank adjacency statistic, is a spatial aggregated measure of spatial autocorrelation used in the studies of epidemiology and medical statistics. Following is the procedure to calculate D-statistic:

Let $z_{i}=\operatorname{rank}\left(y_{i}\right)$ where, $y_{i}$ denotes the number of births for state $i$, $D=\sum \sum\left|z_{i}-z_{k}\right| / \sum \sum w_{i k}$ where, $w_{i k}$ represents the weight of contact or distance between states $i$ and $k$, respectively. We use queen contiguity in which the element $w_{i k}$ is 1 for the adjacent states and 0 otherwise. Spatial clustering (or positive spatial autocorrelation) in the data is reflected by the tendency for adjacent data values to have similar ranks, so that the value of D-statistic will tend to be smaller. Initially, the statistical significance of the pattern had to be established by simulation. For the present study real time data is used in the calculation of D-statistic (see Table 2 ). The theoretical mean and (an approximate) variance of $D$-statistic are derived as $E(D)=\sum \sum E\left(\left|z_{i}-z_{k}\right|\right) / \sum \sum w_{i k}=\frac{n+1}{3}$ and $\operatorname{Var}(D)=([n(n-1)-2 A] / 18 A)$ where, $A$ represents the number of distinct adjacent pairs of states. An approximate $\mathrm{z}$-test of significance postulates the null hypothesis that the data ranks $z_{i}$ are randomly distributed over states. Assuming approximate normality for $\mathrm{D}$ allows a test of significance based on the ratio: $z=[D-E(D)] / \operatorname{sqrt}[\operatorname{Var}(D)]$, with positive spatial autocorrelation leading to negative values of $z$ [21]. 


\section{3. $t$-statistic}

Temporal trends of the number of births are examined based on the following model: $Y_{i t}=\alpha_{i}+\beta t+\varepsilon_{i t}, \quad i=1,2, \ldots, n$, where, $Y_{i t}$ is the birth in state $i$ at time $t, \mathrm{n}$ is the total number of states, respectively. $\alpha_{i}$ is the baseline value for the state $i$, $\operatorname{Cov}\left(\varepsilon_{i t_{1}}, \varepsilon_{i t_{2}}\right)=0$ for distinct $\mathrm{t}_{1}$ and $\mathrm{t}_{2}$ and $\mathrm{i} \neq \mathrm{j} . \varepsilon_{i t}$ forms a Brownian Motion. The hypothesis $\mathrm{H}_{0}$ : $\beta=0$ versus $\mathrm{H}_{1}: \beta \neq 0$ is tested for identifying the temporal trend by estimating the slope $\beta$ (see Table 3 ).

\subsection{Spatial panel models}

In the present article, spatial panel regression models are applied to the selected variables under study which are observed at discrete points in time. Spatial panel facilitates empirical research by extending modelling possibilities which incorporate the dependence among regions in close geographical proximity. General spatial panel model is given as,

$y_{i t}=\tau y_{i t-1}+\rho W y_{i t}+\beta x_{i t}+D z_{i t} \theta+\mu_{i}+\gamma_{t}+v_{i t}$,

$v_{i t}=\lambda e v_{i t}+u_{i t}(i=1,2, \ldots, n ; t=1,2, \ldots, T)$ where $y_{i t}$ and $y_{i t-1}$ represents the level and lagged value of dependent variable, $x_{i t}$ denotes independent variable, $u_{i t}$ is normally distributed error term, $W$ is the spatial matrix for the autoregressive component, $D$ is for the spatially lagged independent variable, $e$ is the spatial weight matrix for error component. $\mu_{i}$ is the individual fixed effect and $\gamma_{t}$ is the time effect. $\rho$ is a measure of spatial dependence between the response variable in different geographic units and $\lambda$ represents autoregressive coefficient for the error terms. Both $\rho$ and $\lambda$ have absolute value less than unity.

Spatial model extends the standard linear regression model for identification of clusters of nearest neighbours allowing dependence among the states [22]. Ordinary Least Square (OLS, henceforth) parameter estimates, in simple linear regression, are based on the first order partial derivative of dependent variable relative to the explanatory variable $x_{k}$ i.e. $\frac{\partial y_{i}}{\partial x_{i, k}}=\beta_{k}$. However, spatial models encompass feedback effect related to the response variable wherein parameter estimates are based on the principle that changes in independent variable for a spatial unit may affect the dependent variable in adjacent units with which it shares boundaries, i.e. $\frac{\partial y_{i}}{\partial x_{i, k}}=f\left(\beta_{k}\right)$, where $f($.) is some mathematical function.

\section{Empirical Analysis}

Initial empirical investigation involves assessment of fertility concentration and transition. 


\subsection{Concentration ratio (CR) of birth}

So far, economists, regional planners and geographers have used location quotient (LQ) to quantify the degree of relative concentration of an activity in the analysis of area localization. We define concentration ratio (CR) to represent birth concentration in a geographic area as

$C R_{t}^{i}=\frac{X}{Y}$ where $X=\left(\frac{B_{t}^{i}}{\sum_{t=1}^{n} B_{t}^{i}}\right)$ and $Y=\left(\frac{T B_{t}}{\sum_{t=1}^{n} T B_{t}}\right), B_{t}^{i}$ represents the level of activity (number of births) at time $t$ in state $i, T B_{t}$ represents the level of activity at time $t$ in the base state and $n$ denotes the number of time points. The value of $C R_{t}^{i}>1 /<1 /=1$ indicates relative birth concentration at timet is more/less/equal compared to the overall India (Table 1).

Table 1. Transition Matrix for the Regions: Pre-2000 and Post-2000.

\begin{tabular}{|c|c|c|c|c|c|c|c|}
\hline \multirow{2}{*}{ Condition } & \multicolumn{4}{|c|}{ Pre-2000 } & \multicolumn{3}{|c|}{ Post-2000 } \\
\hline & 1985 & 1990 & 1995 & 2000 & 2001 & 2006 & 2011 \\
\hline 0 & $\begin{array}{c}\mathrm{AR}, \\
\mathrm{MN}, \\
\mathrm{MZ}, \mathrm{UP}\end{array}$ & SK & AS & BR & JH & & PY \\
\hline 1 & & $\begin{array}{l}\text { AR, AS, } \\
\text { LD, } \\
\text { WB, } \\
\text { MN, } \\
\text { MZ, UP }\end{array}$ & $\mathrm{BR}, \mathrm{MN}$ & & & $\begin{array}{l}\text { BR, JH, } \\
\text { CT, UP, } \\
\text { UT, PY }\end{array}$ & \\
\hline 2 & $\begin{array}{l}\text { SK, AS, } \\
\text { LD, WB }\end{array}$ & & & MN, UP & UP,UT & & $\begin{array}{c}\mathrm{BR}, \mathrm{JH}, \\
\mathrm{CT}, \\
\mathrm{UP}, \mathrm{UT}\end{array}$ \\
\hline
\end{tabular}

Note: Rest of the states do not transit over the time.

AN: Andaman \& Nicobar Islands, AP: Andhra Pradesh, AR: Arunachal Pradesh, AS: Assam, BR: Bihar, CH: Chandigarh, CT: Chhattisgarh, DN: Dadra \&Nagar, DD: Daman \&Diu, DL: Delhi, GA: Goa, GJ: Gujarat, HR: Haryana, HP: Himachal Pradesh, JK: Jammu \&Kashmir, JH: Jharkhand, KA: Karnataka, KL: Kerala, LD: Lakshadweep, MP: Madhya Pradesh, MH: Maharashtra, MN: Manipur, ML: Meghalaya, MZ: Mizoram, NL: Nagaland, OR: Orissa/Odisha, PY: Pondicherry/Puducherry, PB: Punjab, RJ: Rajasthan, SK: Sikkim, TN: Tamil Nadu, TR: Tripura, UP: Uttar Pradesh, UT: Uttarakhand, WB: West Bengal.

For the year 1985, the states AP, MN MZ and UP belong to the high birth cluster. By the year 2000, only two states MN and UP remain in the high birth cluster. The states SK, AS and BR move to low birth cluster post 1990 period, starting from high birth cluster in 1985 . Though high population density regions have higher birth outcomes yet an exception is observed in MN where high births are experienced in 2000, in spite of low population density. The states of Bihar (BR), Jharkhand (JH), Chhattisgarh (CT), Uttar Pradesh (UP) and Uttarakhand 
(UT) transit to the high birth cluster after the year 2000 with the year 2006 being an exception.

High birth clusters shift from Eastern (Assam, Sikkim and West Bengal) and North-Eastern (Uttar Pradesh and Manipur) states to the Northern (Uttar Pradesh and Uttarakhand) grid which eventually diffuses out Southwards (Chhattisgarh) over time. Emergence of a new fertility gradient comprising of an east-west divide across the median length of the northern zone of Indian landmass is seen. Spatial analysis is, thus, motivated by spread of identical fertility patterns along neighbouring pockets.

\subsection{Spatial pattern}

Negative values of the standardized D-statistics indicate spatially auto-correlated (positive) births for the years 1985, 1990, 1995, 2006, 2011 which confirms spatial structuring of fertility levels. Absence of autocorrelation for the years 2000 and 2001 is possibly due to the bifurcation of regions in the year 2000 which lead to division of resources linked to the selected explanatory variables.

Table 2. Results based on the D-statistic.

\begin{tabular}{cccccccc}
\hline & \multicolumn{3}{c}{ Pre-2000 [N=32] } & \multicolumn{3}{c}{ Post-2000 [N=35] } \\
\cline { 2 - 8 } & 1985 & 1990 & 1995 & 2000 & 2001 & 2006 & 2011 \\
\hline $\mathrm{D}$ & -2.4780 & -1.9312 & -2.1509 & 0.3862 & 0.7448 & -1.6260 & -2.1036 \\
\hline
\end{tabular}

\subsection{Temporal transformation}

Table 3 suggests significant decrease in the births for the period (1990 to 1995), while in the next sequential period (1995 to 2000), births show statistically significant increase. This increasing trend continues beyond the year 2000 though they are not statistically significant.

Table 3. Results based on the t-statistic.

\begin{tabular}{lccccc}
\hline Variable(s) & C1990_1985 & C1995_1990 & C2000_1995 & C2006_2001 & C2011_2006 \\
\hline $\mathrm{T}$ & 0.0015 & -1.8252 & 1.9816 & 0.4286 & 0.2869 \\
$\operatorname{Pr}(|\mathrm{T}|>|\mathrm{t}|)$ & 0.9988 & $0.0776 * * *$ & $0.0564 * * *$ & 0.6709 & 0.7759 \\
\hline$* * * \mathrm{p}<.10$ & & & & &
\end{tabular}

\subsection{Non spatial approach}

Analysis of OLS which undertakes comparison between units only, disregarding space and time effects and panel data regression model with fixed effects (PDFE, henceforth), which accounts time effects along with between units effects, are reported in Table 4. PDFE models are more common in empirical investigations compared to random effects studies [23]. Hausman test shows that fixed effects models are more appropriate than the random effects model [24]. As mentioned 
previously that three regions Jharkhand, Uttaranchal and Chhattisgarh were carved out in the year 2000 from Bihar, Uttar Pradesh and Madhya Pradesh respectively. This led to increase in number of spatial units which restricts us from uniform full period (1985-2011) estimation and, thus, results are reported separately for the time spans pre-2000 and post-2000 respectively.

Table 4. Regression results without spatial effect.

\begin{tabular}{lcccc}
\hline & \multicolumn{2}{c}{ Pre-2000 } & \multicolumn{2}{c}{ Post-2000 } \\
\cline { 2 - 5 } & OLS & PDFE & OLS & PDFE \\
\hline Female Literacy & $1.398^{*}$ & $3.730^{*}$ & $1.035^{*}$ & $5.823^{*}$ \\
Male Literacy & $-1.892^{*}$ & $-7.600^{*}$ & -0.517 & $-3.243^{* * *}$ \\
Urbanization & 0.113 & $-0.975^{* *}$ & 0.066 & $-0.743^{*}$ \\
Expenditure & $-0.135^{*}$ & -0.042 & -0.044 & $-0.370^{*}$ \\
Constant & $12.749^{*}$ & $24.686^{*}$ & $7.166^{*}$ & 5.084 \\
\hline$N$ & 390 & 390 & 324 & 324 \\
$R^{2}$ & 0.131 & 0.036 & 0.244 & 0.462 \\
AIC & 714.497 & 528.873 & 255.182 & -175.599 \\
$B I C$ & 734.327 & 548.703 & 274.086 & -156.695 \\
\hline
\end{tabular}

$+\mathrm{p}<.11, * * * \mathrm{p}<.10, * * \mathrm{p}<.05, * \mathrm{p}<.01$

Akaike Information Criterion (AIC) is traditionally used as an aid to select the most suitable competing model among the candidate models which rejects the specific OLS model in favor of the more general PDFE model. Estimation results of both OLS and PDFE indicate that female literacy promotes births significantly while higher male literacy is accompanied by lower occurrences of births for the entire study period. PDFE coefficients indicate that higher government expenditure restricts the birth outcomes. Under PDFE urbanization process results in significantly reduced births, as is expected in the long run.

\subsection{Spatial approach}

Spatial autoregressive (SAR) model hypothesizes that the dependent variable is shaped by the observed dependent variable in neighboring units and on a set of observed local characteristics [25]. The spatial error model (SEM) assumes dependence of response variable on a set of local observed characteristics and serial correlation among error terms across space. Direct (feedback) effects measure impact of change in an explanatory variable on the response variable at a specific location whereas indirect (spatial spillover) effect measures the impact of change in explanatory variable in a specific location on the response variable of the neighbouring location. 
Table 5. Estimation results of spatial autoregressive (SAR) and spatial error (SEM) model.

\begin{tabular}{|c|c|c|c|c|c|}
\hline \multicolumn{4}{|c|}{ SAR } & \multicolumn{2}{|c|}{ SEM } \\
\hline & Pre-2000 & Post-2000 & & Pre-2000 & Post-2000 \\
\hline Main & & & Main & & \\
\hline Female Literacy & $2.019 * *$ & $3.661 *$ & Female Literacy & $2.025 * *$ & $3.455 *$ \\
\hline Male Literacy & $-4.161 * *$ & -0.444 & Male Literacy & $-4.177 * *$ & -0.246 \\
\hline Urbanization & $0.715 * *$ & $-1.247 *$ & Urbanization & $0.717 * *$ & $-1.270 *$ \\
\hline Expenditure & -0.035 & $-0.172 *$ & Expenditure & -0.035 & $-0.176 *$ \\
\hline Constant & & & Constant & & \\
\hline Spatial & & & Spatial & & \\
\hline rho $(\rho)$ & 0.001 & $-0.139 * *$ & lambda $(\lambda)$ & -0.001 & $-0.135 * * *$ \\
\hline Direct & & & & & \\
\hline Female Literacy & $2.011 * *$ & $3.667 *$ & & & \\
\hline Male Literacy & $-4.118 * *$ & -0.388 & & & \\
\hline Urbanization & $0.721 * *$ & $1.248 *$ & & & \\
\hline Expenditure & -0.038 & $-0.175 *$ & & & \\
\hline Indirect & & & & & \\
\hline Female Literacy & -0.024 & $-0.392 * * *$ & & & \\
\hline Male Literacy & 0.046 & 0.047 & & & \\
\hline Urbanization & 0.006 & $0.132 * * *$ & & & \\
\hline Expenditure & -0.001 & $-0.018 * * *$ & & & \\
\hline
\end{tabular}

Results from Table 5 indicate that the estimated coefficients for spatial dependence $(\lambda$ and $\rho$ ) are statistically significant. The estimate for $\lambda$ seems to be larger than the estimate for $\rho$. Under the main effects in both SAR and SEM approaches, increased female literacy favors higher births during the study period whereas increased male literacy causes significant reduction in births. Urban development contradicts its behavior in pre-and post-2000 time periods: rising urban development is accompanied by rise in births in the pre-2000, though it is found to bring down births in post-2000 period significantly. Government spending on infrastructure are seen to substantially bring down the number of births in the study period. Direct effect coefficient estimates are in confirmation with the main effects estimates for SAR model (which account for spatial lag in fertility response) as seen in Table 5. However, indirect effects confirm that the spillover effect of urbanization is much smaller than those from direct feedback effects whereas spillover effect of expenditure is much larger than those from direct effects. Also, female literacy has a negative and male literacy has a positive spillover effect. This is in contrast with a positive feedback impact of female literacy and negative feedback impact of male literacy on the number of births. In other words, the indirect effect coefficients suggest that being surrounded by low educated females, highly educated males, urbane and low government expenditure states discourages higher births in a state.

Spatial Durbin model (SDM, henceforth) accommodates two distinct statistical issues of SAR and SEM regressions which affect regional spatial regression outcomes. This is done by incorporating spatial lag of the dependent 
variable (Wy) and spatial lag of the explanatory variable (WX), respectively, in the same model. For a more transparent comprehension of the induced effects on the actual birth outcome in any state, spatial lags are added to the dependent (and explanatory) variables by considering product Wy (and WX) of spatial weight matrix (queen contiguity matrix $\mathrm{W}$, in the present analysis) and the dependent (and explanatory) variables, as presented in Table 6. Wy (and WX) represents interactions between endogenous (and exogenous) characteristics of nearby observations with response variable at the location. The main objective of introducing a spatial lag is to obtain an average value that exists in the neighbouring regions.

Table 6. Estimation results for standard SDM fixed effects models.

\begin{tabular}{lcccc}
\hline \multirow{2}{*}{ Variable } & \multicolumn{2}{c}{ Pre-2000 } & \multicolumn{2}{c}{ Post-2000 } \\
\cline { 2 - 5 } & Coefficients & $\begin{array}{c}\text { Standard } \\
\text { errors }\end{array}$ & Coefficients & Standard errors \\
\hline Female Literacy & 1.9820 & $0.9240^{* *}$ & 3.0036 & $0.7131^{*}$ \\
Male Literacy & -4.3887 & $1.9568^{* *}$ & -2.2936 & 1.5723 \\
Urbanization & 0.7427 & $0.3009^{* *}$ & -1.3955 & $0.1486^{*}$ \\
Expenditure & -0.0871 & 0.0631 & -0.0938 & $0.0555^{* * *}$ \\
W*Female Literacy & 0.9799 & 1.4801 & 2.0192 & 1.3667 \\
W*Male Literacy & -3.9387 & 3.5449 & -3.4301 & 2.7655 \\
W*Urbanization & 0.0556 & 0.7924 & -1.5827 & $0.4110^{*}$ \\
W*Expenditure & 0.3418 & $0.1400^{* *}$ & 0.0606 & 0.0801 \\
Spatial dependence (rho) & -0.0031 & 0.0593 & -0.1048 & 0.0736 \\
\hline
\end{tabular}

Results of Table 6 show that the occurrence of births are positively related to female education and negatively related to male literacy and social infrastructure expenditure incurred by the government in the region. Urbanisation positively influences births in the pre-2000 period and helps in controlling birth counts in the post-2000 period. On adding spatial lags for the explanatory variable (WX) effects of female and male education remain same as before. However, such conjunction reverses the association between fertility outcome and social infrastructure expenditure. In other words, education effect of both the genders remained unchanged in the state as well as in its neighbouring region, however, higher social infrastructure spending in one region is found to be beneficial for the state itself but disadvantageous for the neighbouring states. Urbanisation reduces the number of births though more in the state itself than in the surrounding regions.

In the SDM estimation, a change in explanatory variable in a region has a direct influence on the specific region and an indirect effect on the surrounding adjacent regions. The results in Table 6 does not segregate the contribution of direct and indirect effects of explanatory variables on the fertility outcomes. Table 7 gives computation of total, direct and indirect effects for a succinct interpretation of the estimated coefficients [26]. 
The above micro analysis gives a clearer picture of the spatial fertility dynamics in the states of India during the 27 year time span of the current empirical study. Coefficients of the total effects are in agreement with the direct effect coefficients with the exception of expenditure variable in pre-2000. By separating tangible (direct) and intangible (indirect) forces associated with each factor we find that in the post-2000 period, spillover from female literacy and urbanization results in diminishing births and spillover impact of male literacy boosts births in the neighborhoods. Rest of the coefficient estimates show that the influences of the selected explanatory variables remain in line with the interpretation of coefficients from the earlier spatial models.

Table 7. Direct, indirect and total effects of SDM model.

\begin{tabular}{|c|c|c|c|c|c|c|}
\hline \multicolumn{7}{|c|}{ Pre-2000 } \\
\hline & \multicolumn{2}{|c|}{ Direct } & \multicolumn{2}{|c|}{ Indirect } & \multicolumn{2}{|c|}{ Total } \\
\hline & $\begin{array}{l}\text { Coefficie } \\
\text { nts }\end{array}$ & $\begin{array}{l}\text { Standard } \\
\text { errors }\end{array}$ & $\begin{array}{l}\text { Coeffici } \\
\text { ents }\end{array}$ & $\begin{array}{l}\text { Standard } \\
\text { errors }\end{array}$ & $\begin{array}{l}\text { Coeffic } \\
\text { ients }\end{array}$ & $\begin{array}{l}\text { Standard } \\
\text { errors }\end{array}$ \\
\hline $\begin{array}{l}\text { Female } \\
\text { Literacy }\end{array}$ & 1.9656 & $0.8573 * *$ & 1.0309 & 1.3251 & 2.9965 & $1.5681 * * *$ \\
\hline $\begin{array}{l}\text { Male } \\
\text { Literacy }\end{array}$ & -4.3214 & $1.8549 * *$ & -3.8140 & 3.1786 & -8.1354 & $3.8793 * *$ \\
\hline Urbanization & 0.7524 & $0.3126 * *$ & -0.0071 & 0.8053 & 0.7453 & 0.8145 \\
\hline Expenditure & -0.0888 & 0.0611 & 0.3071 & $0.1296 * *$ & 0.2182 & $0.1202 * * *$ \\
\hline \multicolumn{7}{|c|}{ Post-2000 } \\
\hline $\begin{array}{l}\text { Female } \\
\text { Literacy }\end{array}$ & 3.0517 & $0.6086^{*}$ & -1.8598 & $1.1204 * * *$ & 1.1919 & 1.3098 \\
\hline $\begin{array}{l}\text { Male } \\
\text { Literacy }\end{array}$ & 2.2825 & 1.4674 & 2.5458 & 2.1657 & 4.8283 & $2.9153 * * *$ \\
\hline Urbanization & -1.3558 & $0.1534 *$ & -1.2667 & $0.3651 *$ & -2.6224 & $0.3804 *$ \\
\hline Expenditure & -0.0952 & $0.0557 * * *$ & 0.0475 & 0.0712 & -0.0476 & 0.0672 \\
\hline
\end{tabular}

\section{Discussion}

Bihar, Uttar Pradesh, Jharkhand, Madhya Pradesh and Rajasthan report very high rate of fertility compared to the rest of the Indian states. One of the striking commonality is that these states share boundaries with one or the other mentioned states. This "striking" commonality intuitively indicates possible presence of spatial correlation in fertility rates across these states and thus, motivates us to examine the spatial distribution of fertility. The spatial units considered were states and union territories between 1985 and 2011. Explanatory variables were identified using significant D-statistics. Objective of the present article was to identify and analyse factors influencing regional births at spatial scale (Indian states and union territories) using spatial panel data models. A systematic examination of the selected factors was carried out using OLS, PDFE, SAR, SEM and SDM in order to assess the extent of their influence on the birth outcomes in the same region as well as in the adjacent regions. Direct effects indicate that birth 
decline is fostered by lower female education, higher male education, lower urbanisation and higher social infrastructure expenditure in pre-2000 period while post-2000 period analysis shows reversal in male education and urbanisation effects alone. Feedbacks are larger in strength than spillovers for the entire study period as obtained from both SAR and SDM regressions for all the considered covariates with the exception being male literacy spillovers from SDM in post2000 .

In the SDM, when direct and indirect effects are disentangled then all the four potential determinants considered in the study show positive spatial spillover impact on the neighbouring regions for the entire study period. This means that a region located in a neighbourhood with educated people, good infrastructure and higher urbanisation will tend to have higher actual birth outcomes. This could be interpreted as an urbanised region with better infrastructure spending will attract investment away from neighbouring rural regions with poorer infrastructure. Expansion of infrastructure expenditure (towards development, for example through institutional settings in form of hospitals and schools) should therefore be encouraged by the state administration in all the spatially adjacent units, so that the inherent positive direct effects benefit each state. In general, urbanisation effects are percolated in any region only in the long run. This fact finds support in our study where urbanisation has positive effect in pre 2000 period and negative effect on post 2000 period, on the birth outcomes. Therefore, urban facilities (such as roads, electrification and safe drinking water) should be continuously and uniformly provided by the planners and local government, so as to achieve birth decline both in the states and is neighbouring regions. Such interpretation of the influencing patterns lead to an understanding that regions with similar attributes (other things being equal) can have different fertility rates if neighbouring regions differ with respect to these four characteristic features.

\section{Conclusion}

Many researchers have identified and studied causal forces which influence decline in Indian fertility or fertility in specific states of India. However, the novel contribution of the present paper is to understand the net influence of the selected causal forces in the self state (feedback effect) as well as in the states which share geographic boundary with it (spillover effect) over a period of time. The present paper is the first attempt in the spatial context of states in India (to the best of our knowledge) which disengage direct and indirect effects to study feedback effects of female literacy, male literacy, urbanization and infrastructure expenditure on the actual fertility outcomes, in addition to acknowledging spillover effects of these causal forces among the neighbouring states of India. Specifically, this manuscript constitutes a quantitative study of diffusion process which brings about 
fertility variations across states in India as they experience educational, economic and social infrastructure changes over time.

\section{Acknowledgments}

First author gratefully acknowledges financial assistance from Research and Development grant by University of Delhi. The work of second author is supported by ICMR Grant No. 3/1/3/JRF-2010/HRD-122 (35831).

\section{Appendix}

Table A.1. Definition of variables used in study.

\begin{tabular}{|l|l|}
\hline Variable & Definition \\
\hline \multirow{3}{*}{ Births } & $\begin{array}{l}\text { This variable denotes the number of registered live births in } \\
\text { states of India. }\end{array}$ \\
\cline { 2 - 2 } & Births are normalised with respect to population (in log form) \\
\hline \multirow{3}{*}{ Literacy Rate } & The percentage of the people with the ability to read and write. \\
\cline { 2 - 2 } Urbanization Rate & Female Literacy Rate (in log form) \\
\cline { 2 - 2 } Social Infrastructure & The level of urban development relative to overall population. \\
\cline { 2 - 2 } Expenditure & Urbanization (in log form) \\
\hline \multirow{5}{*}{$\begin{array}{l}\text { Total social infrastructure expenditure consists of expenditure } \\
\text { on Education, Sports, Art and Culture; Medical and Public }\end{array}$} \\
$\begin{array}{l}\text { Health; Family Welfare; and Urban Development. For per } \\
\text { capita social infrastructure expenditure, it is divided by } \\
\text { population. }\end{array}$ \\
\cline { 2 - 2 } & Per capita social infrastructure expenditure (in log form) \\
\hline
\end{tabular}

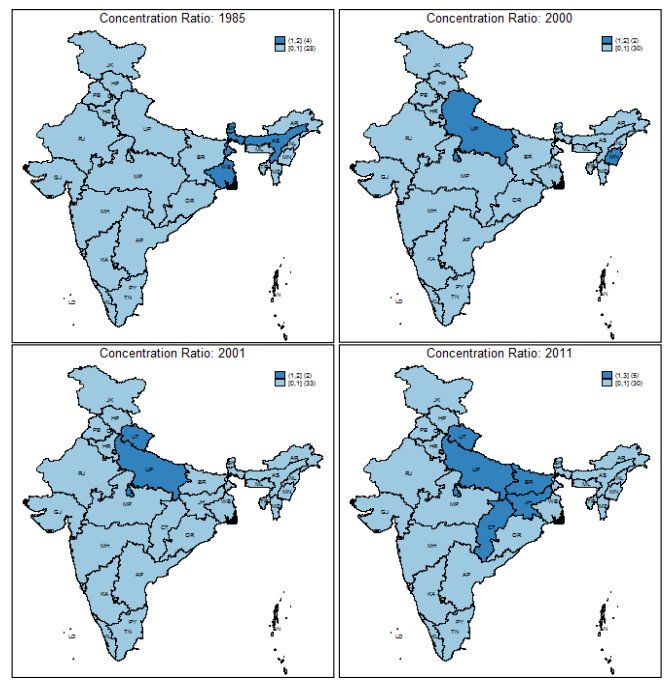

Fig. A.1. Fertility transition profile based on concentration ratio. 


\section{References}

1. G. Becker, Am. Economic Rev. 78, 1 (1988).

2. D. J. V. Kaa, Population Studies 50(3), 389 (1996). https://doi.org/10.1080/0032472031000149546

3. W. G. Robinson, Studies 51(1), 63 (1997).

4. P. Dommarajuand and V. Agadjanian, J. Population Res. 26(3), 249 (2009). https://doi.org/10.1007/s12546-009-9014-5

5. T. Spoorenberg and P.Dommaraju, Int. J. Population Res. 2012, 1 (2012). https://doi.org/10.1155/2012/358409

6. S. Kazi and and Z. A. Sathar, Pak. Development Rev. 32(4 Pt 2), 887 (1993).

7. United Nations, Women's Employment and Fertility: A Comparative Analysis of World Fertility Survey Results from 38 Developing Countries, Population Studies No. 96, New York: United Nations Department of Economic and Social Affairs (1985).

8. M. L. Brookinsand and O.T. Brookins, J. Development Studies 39(2), 54 (2002). https://doi.org/10.1080/00220380412331322751

9. C. Oppong, Women's Roles, Opportunity Costs and Fertility, In Determinants of Fertility in Developing, ed. R. A. Bulatao et al. (Academic Press, New York, 1983) pp. 439-473.

10. J. C. Caldwell, Population Studies 35, 5 (1981). https://doi.org/10.2307/2174833

11. P. N. M. Bhat and A. J. F. Zavier, Demography 40(4), 637 (2003). https://doi.org/10.2307/1515201

12. P. N. M. Bhat, World Development 30(10), 1791 (2002). https://doi.org/10.1016/S0305-750X(02)00065-7

13. K. McNay, P. Arokiasamy, and R. H. Cassen, Population Studies 5(1), 21 (2003). https://doi.org/10.1080/0032472032000061703

14. P. Arokiasamy, Economic and Political Weekly XLIV(30), 55 (2009).

15. R. Pandey and C. Kaur, Chinese J. Population Res. Environ. 13(4), 349 (2015). https://doi.org/10.1080/10042857.2015.1111573

16. P. Arokiasamy and S. Goli, Genus LXVIII(I), 65 (2012)

17. C. Z. Guilmoto, Contemporary Demographic Transformation in China, India and Indonesia (Springer, Switzerland, 2016) 5, pp. 113-132.

18. A. Dharmalingam, S. Rajan, and S. P. Morgan, Demography 51(4), 1451 (2014). https://doi.org/10.1007/s13524-014-0314-9

19. Centre for Monitoring Indian Economy (CMIE), States of India, Accessed on 14/8/2014. http://statesofindia.cmie.com/

20. NIUA, Urban Statistics-Hand Book 2000, New Delhi: National Institute of Urban Affairs, (2000).

21. S. D. Walter, Statistics Medicine 13(10), 1037 (1994). https://doi.org/10.1002/sim.4780131006

22. L. Anselin, Spatial Econometrics: Methods and Models, (Kluwer Academic Publishers, Dordrecht, 1988). https://doi.org/10.1007/978-94-015-7799-1

23. S. N. Durlauf, P. A. Jhonson, and J. R. W.Temple, Growth Econometrics, Handbook of Economic Growth, ed. P. Aghion et al. (Elsevier, Amsterdam : North Holland, 2005).

24. G. M. Resende, A. X. Y. Carvalho, P. A. M. Sakowski, and T. A. Cravo, Ann. Reg. Sci. 56, 1 (2016). https://doi.org/10.1007/s00168-015-0706-9

25. L. Anselin, J. L. Gallo, and H. Jayet, Spatial Panel Econometrics, In The Econometrics of Panel Data, ed. L. Mátyás et al. (Springer, New York, 2008) pp. 625-659. https://doi.org/10.1007/978-3-540-75892-1_19

26. J. P. Lesageand and R. K. Pace, Introduction to Spatial Econometrics (Chapman and Hall/CRC Press, U.S.A., 2009). https://doi.org/10.1201/9781420064254 